\title{
Ocular manifestations in children and adolescents with Lyme arthritis
}

\author{
Hans-Iko Huppertz, Doris Münchmeier, Wolfgang Lieb
}

\begin{abstract}
Background-Lyme arthritis is the most frequent late manifestation of Lyme borreliosis and has been associated with ocular inflammation.

Methods-A group of 153 children and adolescents with arthritis, 84 of whom had Lyme arthritis and 69 other causes of arthritis, were followed prospectively for 22-73 (median 44) months in the course of a national study.

Results-Three of 84 patients with Lyme arthritis had ocular inflammation (4\%), including keratitis, anterior uveitis, and uveitis intermedia. All three had symptoms of decreased visual acuity. Whereas anterior uveitis disappeared without sequelae, a corneal scar and a permanent loss of visual acuity in the patients with keratitis and intermediate uveitis remained. Systematic examination of all patients revealed no further ocular involvement. Of 69 patients with other causes of arthritis who were followed in parallel as a control group, four of 15 patients with early onset pauciarticular juvenile rheumatoid arthritis had chronic anterior uveitis and two of 12 patients with juvenile spondyloarthropathy had acute anterior uveitis.

Conclusions-Ocular involvement with keratitis, anterior uveitis, and intermediate uveitis may occur in children and adolescents with Lyme arthritis. Visual loss appears to be symptomatic, making regular ocular screening of such patients unnecessary.

(Br F Ophthalmol 1999;83:1149-1152)
\end{abstract}

Children's Hospital, University of

Würzburg, Würzburg, Germany

H-I Huppertz

D Münchmeier

Department of

Ophthalmology,

University of

Würzburg, Würzburg,

Germany

W Lieb

Correspondence to:

Professor Dr med Hans-Iko

Huppertz,

Zentralkrankenhaus

Sankt-Jürgen-Strasse,

Professor-Hess-Kinderklinik,

28205 Bremen, Germany.

Accepted for publication 25 July 1999 including anterior uveitis, intermediate uve tis, and keratitis have been described during late stages of the disease. ${ }^{34}$ Severe cases may lead to blindness. ${ }^{5}$ Ocular involvement has also been found in an animal model of Lyme borreliosis. $^{7}$

Ocular Lyme borreliosis has also been reported in children. ${ }^{8-14}$ For example, two cases of late keratitis have been described in a group of 46 American children with Lyme arthritis. ${ }^{9}$ In view of these reports we have investigated the occurrence of inflammatory eye disease in a large cohort of European children with Lyme arthritis. Specifically we wanted to know if regular screening for eye involvement in patients with Lyme arthritis is warranted.

\section{Patients and methods}

In 1991 we started a prospective multicentre study to investigate the late manifestations of Lyme borreliosis in European children and adolescents. Physicians were encouraged to enter patients when they suspected Lyme arthritis. ${ }^{1516}$ Patients in whom arthritis had started before their 16 th birthday, were included if the attending physician considered that they might have Lyme arthritis.

Clinical data were recorded and all patients were tested for IgG and $\operatorname{IgM}$ antibodies to $B$ burgdorferi in our laboratory using in-house ELISA and immunoblot methods. ${ }^{15}$ Lyme arthritis was diagnosed on the basis of a positive ELISA and immunoblot analysis $(\geqslant 6$ specific bands) for IgG antibodies to $B$ burgdorferi. These criteria for interpretation of immunoblot analysis are considered equivalent to the Dearborn criteria published after the initiation of this study. ${ }^{17} 18$

In some patients, serum was also tested for antibodies to $B$ burgdorferi using the haemagglutination assay (HAT) (Biologische Arbeitsgemeinschaft, Lich, Germany). Peripheral blood lymphocytes were tested for reactivity to borrelial antigens ${ }^{19}$ and urine was examined using the polymerase chain reaction for the presence of a B burgdorferi specific segment of a gene encoding for the $41 \mathrm{kD}$ flagellin. ${ }^{20}$

Patients not fulfilling the criteria for Lyme arthritis who had other causes of arthritis were also followed:

- Reactive arthritis associated with a Salmonella, Yersinia, Chlamydia, Mycoplasma, or parvovirus B19 infection and with diarrhoea, urethritis, or the typical rash preceding arthritis. Diagnosis was confirmed by culture, polymerase chain reaction, or serology.

- Juvenile spondyloarthropathy, where the onset of arthritis occurred before the age of 16 years, was diagnosed according to the European Spondyloarthropathy Study Group (ESSG) criteria. ${ }^{21}$ 
Table 1 Diagnosis of 69 paediatric control patients with causes of arthritis other than Lyme borreliosis

\begin{tabular}{lc}
\hline Diagnosis & $\begin{array}{l}\text { No of } \\
\text { patients }\end{array}$ \\
\hline Early onset pauciarticular JRA & 15 \\
Rheumatoid factor negative polyarticular JRA & 1 \\
Oligoarticular JRA without subclassification & 16 \\
Acute transient arthritis & 12 \\
Reactive arthritis & 11 \\
Juvenile spondyloarthropathy & 12 \\
Septic arthritis & 1 \\
Vasculitis, non-classified & 1 \\
\hline
\end{tabular}

- Pauciarticular juvenile rheumatoid arthritis, rheumatoid factor negative polyarticular juvenile rheumatoid arthritis, and oligoarticular juvenile rheumatoid arthritis without subclassification were diagnosed according to the American College of Rheumatology, formerly American Rheumatism Association, classification. ${ }^{22}$

- Arthritis, including toxic synovitis of the hip, having a duration of less than 6 weeks, was classified as acute transient arthritis. ${ }^{23}$ As stated in the study protocol, ocular manifestations were recorded by the attending physicians, mainly paediatric rheumatologists, at each scheduled visit 3 months, 1,3 , and 5 years after entering the study. In addition to routine ophthalmological care provided as needed, all patients were sent for ophthalmological assessment by an ophthalmologist of the patient's preference at the 3 year follow up examination. To ensure uniformity in ophthalmological examination, patients were asked to present an accompanying letter to the attending ophthalmologist explaining the purpose of the study. The letter listed, in anatomical order, all ocular manifestations of Lyme borreliosis described in the literature so far, beginning with keratitis and conjunctivitis and ending with retinal problems. Neuro-ophthamological entitiesthat is, papilloedema and optic nerve neuritis, and squint were also listed. Ophthalmologists were asked to report all abnormalities irrespective of their opinion on whether they were related to Lyme borreliosis or not.

The study was approved by the ethics committee of the medical faculty of the University of Würzburg. Informed consent was obtained from the patients' parents and from adolescent patients themselves.

Statistical analysis was performed with the help of the MEDAS system. ${ }^{24}$

\section{Results}

The records of 153 children and adolescents who had been examined at least once by one of 114 ophthalmologists in Germany and Switzerland $(n=1)$ were available for analysis. The

Table 2 Ocular involvement other than transient conjunctivitis in 153 children and adolescents with arthritis after a median follow up of 44 months

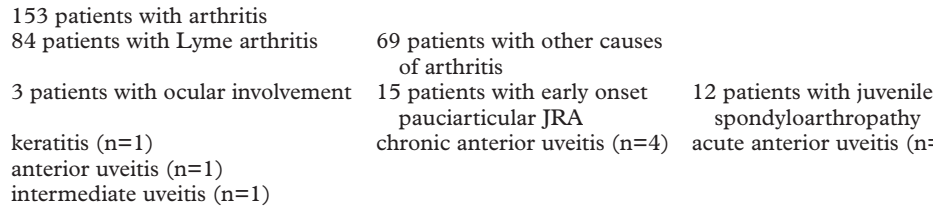

last ophthalmological assessment was performed after a period of 44 months (median, range $22-73$ months) after entering the study.

Lyme arthritis was diagnosed in 84 patients of which $49(58 \%)$ were male with a median age at the time of entry to the study of 11 years 7 months (range 2 years 8 months- 16 years 8 months). The remaining 69 patients had other causes of arthritis (Table 1) and served as the control group: $32(46 \%)$ were male with a median age of 8 years 8 months (range 1 year-16 years 1 month).

Inflammatory eye lesions were reported in 10 control patients and in nine patients with Lyme arthritis. Transient conjunctivitis was found in four control patients $(6 \%)$ and in six patients with Lyme arthritis (7\%). Of the 69 control patients, six patients had inflammatory eye lesions other than transient conjunctivitis (9\%) and of the 84 patients with Lyme arthritis, three patients had other inflammatory eye lesions $(4 \%)$ (Table 2 ).

Of the control patients, two male HLA B27 positive patients of 12 patients with juvenile spondyloarthropathy (17\%) had acute anterior uveitis and four of 15 patients with early onset pauciarticular juvenile rheumatoid arthritis $(27 \%)$ had chronic anterior uveitis. Three of these patients were girls and all four were antinuclear antibody positive.

Of 84 patients with Lyme arthritis, three patients $(4 \%)$ had ocular lesions other than transient conjunctivitis; clinical details are shown in Table 3. All eye diseases came to light following complaints by the patients and not as a result of the routine ophthalmological examinations or during the 3 year examination done with special reference to signs and symptoms of ocular Lyme borreliosis. Two patients had lagophthalmus and facial nerve palsy before the onset of Lyme arthritis. No other neuroophthalmological manifestations were noted during the entire period of observation.

Patient no 1, a 13 year old girl, reported loss of vision 10 months after onset of episodic arthritis of the right knee. Intermediate uveitis was diagnosed and treated with topical and systemic steroids. A diagnosis of Lyme borreliosis was made when antibodies to B burgdorferi were detected in the patient's serum and she was then treated with systemic tetracyclines. Since arthritis recurred and vision deteriorated further, she was treated with ceftriaxone and bilateral pars plana vitrectomy. Arthritis disappeared and uveitis abated with permanently reduced visual acuity.

Patient no 2 had episodic arthritis of the knee which was diagnosed as Lyme arthritis only 3 years after its onset. The patient was initially given intravenous penicillin and then ceftriaxone when the arthritis recurred. Although arthritis had disappeared 3 months later, the patient developed severe keratitis of the upper third of both corneas with marked neovascularisation, but without intraocular inflammation. Keratitis resolved after treatment with topical steroids, but corneal scars were still present 2 years later.

Patient no 3 had episodic arthritis of the right knee and elbow which was treated with 
Table 3 Clinical data of three patients with ocular borreliosis

\begin{tabular}{|c|c|c|c|c|c|c|c|c|c|c|c|}
\hline $\begin{array}{l}\text { Patient } \\
\text { no }\end{array}$ & $\begin{array}{l}\text { Age } \\
\text { (years) }\end{array}$ & Sex & Ocular symptoms & Other symptoms & $\begin{array}{l}\text { Elisa } \\
\operatorname{IgM/IgG}\end{array}$ & $\begin{array}{l}H A T \\
(1: n)\end{array}$ & $\begin{array}{l}\text { Immunoblot } \\
\operatorname{IgM} / \operatorname{IgG}\end{array}$ & $\begin{array}{l}\text { Lymphocyte } \\
\text { proliferation } \\
\text { assay }\end{array}$ & $\begin{array}{l}\text { PCR in } \\
\text { urine }\end{array}$ & Treatment & $\begin{array}{l}\text { Outcome } \\
\text { (visual acuity) }\end{array}$ \\
\hline 1 & 13 & $\mathrm{~F}$ & $\begin{array}{l}\text { bilateral intermediate } \\
\text { uveitis, right retinal } \\
\text { detachment }\end{array}$ & $\begin{array}{l}\text { arthritis right } \\
\text { knee }\end{array}$ & $+/+$ & 5120 & $+/+$ & + & + & \multirow{3}{*}{$\begin{array}{l}\text { systemic/topical } \\
\text { steroids } \\
\text { tetracyclines, } \\
\text { ceftriaxone } \\
\text { bilateral vitrectomy } \\
\text { topical steroids } \\
\text { penicillin G, } \\
\text { ceftriaxone } \\
\text { topical steroids } \\
\text { ceftriaxone }\end{array}$} & $\begin{array}{l}\text { R } 0.25 \\
\text { L } 0.8\end{array}$ \\
\hline 2 & 14 & M & $\begin{array}{l}\text { bilateral superior keratitis } \\
\text { with neovascularisation }\end{array}$ & $\begin{array}{l}\text { arthritis right } \\
\text { knee }\end{array}$ & $-/+$ & 20.480 & $-/+$ & + & - & & $\begin{array}{l}\text { recovery with } \\
\text { corneal scars }\end{array}$ \\
\hline 3 & 6 & $\mathrm{~F}$ & bilateral anterior uveitis & $\begin{array}{l}\text { arthritis right } \\
\text { knee and right } \\
\text { elbow }\end{array}$ & $-/+$ & 10.240 & $-/+$ & + & - & & $\begin{array}{l}\text { recovery } \\
\text { R } 1.0 \\
\text { L } 1.0\end{array}$ \\
\hline
\end{tabular}

ceftriaxone. Arthritis recurred 3 years later, however, and the patient developed blurred vision along with a continuously high titre for antibodies to $B$ burgdorferi. Bilateral anterior uveitis was detected. The parents of the patient withheld their consent to start antibiotic treatment although no other cause of the inflammatory eye and joint disease was found. Symptoms abated spontaneously during the next few months and did not recur during the following 3 years, when the antibody titre began to decline.

\section{Discussion}

We have described three patients with Lyme arthritis who developed ocular borreliosis. In the group of patients examined by us, this represents a frequency of $4 \%$ which is the same as that found in American children with Lyme arthritis. ${ }^{9}$ Whereas the American children developed keratitis however, the clinical manifestations in the German children were more varied and included intermediate uveitis and anterior uveitis, in addition to keratitis.

Keratitis, occurring in the absence of live spirochaetes and being associated with the deposition of antigen-antibody complexes, is a late manifestation rarely seen in children ${ }^{9}$ and in adults with Lyme borreliosis. ${ }^{3}$ Although several types of keratitis have been associated with Lyme borreliosis, peripheral ulcerative keratitis with abundant neovascularisation, as seen in patient no 2 , seems characteristic. ${ }^{25}$ In patient no 2 , keratitis occurred after successful antibiotic treatment of Lyme arthritis. Although corneal scars may occur, the treatment of choice is topical corticosteroids. ${ }^{4}$

Intermediate uveitis due to infection with $B$ burgdorferi is also rarely seen in children. ${ }^{11}{ }^{12}{ }^{14}$ In adults, Lyme borreliosis has been described as a cause of intermediate uveitis with vitreitis. ${ }^{34}$ Recommended treatment includes the use of antibiotics and good results have been reported with intravenous ceftriaxone. ${ }^{26}$ The recommended dose of ceftriaxone is 50 $\mathrm{mg} / \mathrm{kg}$ body weight although larger doses have also been used. As seen in patient no 1 , however, visual acuity may remain diminished after inflammation has abated.

Anterior uveitis is the most frequent intraocular inflammatory disease and is associated with a large variety of infectious disorders and autoimmune diseases including early onset pauciarticular juvenile rheumatoid arthritis and juvenile spondyloarthropathy as found in six of our control patients. Because of these observations, the existence of a causal relation between anterior uveitis and infection with $B$ burgdorferi was questioned, ${ }^{27}$ but the subsequent isolation of $B$ burgdorferi from the inflamed iris is evidence to support a borrelial aetiology of some cases of anterior uveitis. ${ }^{28}$ Although anterior uveitis is rarely observed in children with Lyme borreliosis, ${ }^{8}{ }^{11}$ no alternative explanation for its occurrence in patient no 3 was found. Despite the fact that antibiotic treatment was refused, articular and ocular inflammation disappeared when antibody titres declined. As with other manifestations of Lyme borreliosis, the disease may disappear spontaneously in the absence antibiotic treatment, but there is a risk that it may recur and even progress to more serious manifestations. The recommended treatment is therefore administration of antibiotics-ceftriaxone together with topical steroids and, in severe cases, systemic steroids-prednisone at 1-2 $\mathrm{mg} / \mathrm{kg}$ body weight. ${ }^{34}$

Transient conjunctivitis occurring at the time of erythema migrans and influenza-like symptoms have been described in the early stage of Lyme borreliosis. ${ }^{3}$ Since in this study all patients with Lyme borreliosis were in the late stage of the disease, conjunctivitis, which was observed in six patients with Lyme arthritis, is not considered to be due to infection with $B$ burgdorferi. This conclusion is corroborated by the observation that conjunctivitis occurred with a similar frequency among the control patients.

Eye involvement in Lyme borreliosis occurs most frequently in the course of neuroborreliosis: in addition to facial nerve palsy, a variety of manifestations have been reported. ${ }^{529-31}$ In this study, in children with Lyme arthritis, these manifestations were not seen.

Although the patient data in this study were contributed by a large number of ophthalmologists, sampling errors do not seem to be present. This conclusion is supported by two observations: (i) the frequency of transient conjunctivitis due to viral infection or allergy was nearly identical in patients with Lyme arthritis and in the control group; (ii) acute anterior uveitis was found in two of 12 children with juvenile spondyloarthropathy and anterior uveitis in four of 15 children with early onset pauciarticular juvenile rheumatoid arthritis. The type of ocular involvement, the association with specific rheumatic disease and the 
observed frequency were in accordance with current knowledge. ${ }^{32}$

In addition to seronegative Lyme arthritis, ${ }^{33}$ choroiditis and vitritis due to infection with $B$ burgdorferi has been described in a single patient negative for antibodies to $B$ burgdorferi. ${ }^{34}$ In the present study, the diagnosis of Lyme borreliosis required the presence of high titres of antibodies specific for $B$ burgdorferi and therefore cases of seronegative Lyme borreliosis would have been missed. However, such cases occur only rarely and diagnosis should be confined to centres with special expertise in this regard.

Although this was not examined in the present study, the comparison of our data in children and adolescents with those reported in adult patients with ocular manifestations in Lyme borreliosis does not reveal major differences. ${ }^{34}$

Patients with early onset pauciarticular juvenile rheumatoid arthritis may develop anterior uveitis in the absence of signs or symptoms and severe intraocular damage may occur before the disease is detected. Therefore, regular ophthalmological examination is recommended in these patients. In all three patients with Lyme arthritis reported here, ocular inflammation was first seen following the reporting of signs and symptoms by the patient and/or their parents and did not come to light as the result of the routine ophthalmological examination. In fact, neither the special ophthalmological appointment 3 years after the onset of antibiotic treatment nor the routine ophthalmological examinations revealed any additional ocular pathology in the patients that was not previously known. Thus, patients with Lyme arthritis may develop ocular disease, but they need not be screened for this on a regular basis.

We are extremely grateful to the participating ophthalmologists and paediatricians for examining and referring their patients, Hygiene and Microbiology of the University of Würzburg, for performing borrelial serology and the polymerase chain reaction.

1 Böhme M, Standaert SM, Karch H, et al. Lyme borreliosis - second most common bacterial disease in Germany. Arthritis Rheum 1997;40:S124.

2 Steere AC. Lyme disease. N Engl f Med 1989;321:586-96.

3 Berglöff J, Gasser R, Feigl B. Ophthalmic manifestations in Lyme borreliosis. F Neuro-ophthalmol 1994;14:15-20.

Lyme borreliosis. F Neuro-ophthalmol 1994;14:15-20.
Zaidman GW. The ocular manifestations of Lyme disease. Zaidman GW. The ocular manifestatio
Int Ophthalmol Clin 1997;37:13-28.

5 Arnold RW, Schriever G. Lyme amaurosis in a child. 7 Pediatr Ophthalmol Strabismus 1993;30:268-70.

6 Steere AC, Duray PH, Kauffmann DJH, et al. Unilateral blindness caused by infection with the Lyme disease spirochete, Borrelia burgdorferi. Ann Intern Med 1985;103 382-4
7 Philipp M, Aydintug MK, Bohm RP, et al. Early and early disseminated phases of Lyme disease in the rhesus monkey: model for infection in humans. Infect Immun 1993;61: a model

8 Winward KE, Smith JL, Culbertson WW, et al. Ocular Lyme borreliosis. Am f Ophthalmol 1989;108:651-7.

9 Szer IS, Taylor E, Steere AC. The long-term course of Lyme arthritis in children. N Engl f Med 1991;325:159-63.

10 Mombaerts IM, Maudgal PC, Knockaert DC. Bilateral follicular conjunctivitis as a manifestation of Lyme disease. Am $\mathcal{F}$ Ophthalmol 1991;112:96-7.

11 Reim H, Reim M. Augenbefunde bei Infektion mit Borrelia burgdorferi. Klin Monatsbl Augenheilkd 1992;201:83-91.

12 Guex-Crosier Y, Herbort CP. Maladie de Lyme en Suisse: Guex-Crosier Y, Herbort CP. Maladie de Lyme en Suisse: 545-6.

13 Karma A, Pirttilä TA, Viljanen MK, et al. Secondary retinitis pigmentosa and cerebral demyelination in Lyme borreliosis. Br f Ophthalmol 1993; 77:120-2.

14 Karma A, Seppälä I, Mikkilä H, et al. Diagnosis and clinical charateristics of ocular Lyme borreliosis. Am $\mathcal{f}$ Ophthalmol 1995;119:127-35.

15 Huppertz HI, Karch H, Suschke HJ, et al, Pediatric Rheumatology Collaborative Group. Lyme arthritis in European children and adolescents. Arthritis Rheum 1995; 38:361-8.

16 Huppertz HI, Bentas W, Haubitz I, et al. Diagnosis of pediatric Lyme arthritis using a clinical score. Eur $\mathcal{f}$ Pediatr 1998:157:304-8.

17 Recommendations for test performance and interpretation from the second national conference on serologic diagnosis of Lyme disease. MMWR 1995;44:590.

18 Dressler F, Whalen JA, Reinhart BN, et al. Western blotting in the serodiagnosis of Lyme disease. F Infect Dis 1993;167: 392-400.

19 Huppertz HI, Mösbauer S, Busch DH, et al. Lymphoproliferative responses to Borrelia burgdorferi in the diagnosis of Lyme arthritis in children and adolescents. Eur $\mathcal{F}$ Pediatr 1996;155:297-302.

20 Karch H, Huppertz HI, Böhme M, et al. Demonstration of Borrelia burgdorferi DNA in urine samples from healthy humans whose sera contain Borrelia burgdorferi-specific antibodies. 7 Clin Microbiol 1994:32:2312-14.

21 Dougados M, van der Linden S, Juhlin R, et al. The European Spondyloarthropathy Study Group preliminary criteria for the classification of spondyloarthropathy. Arthritis Rheum 1991;34:1218-27.

22 Cassidy JT, Levinson JE, Bass JC, et al. A study of classification criteria for a diagnosis of juvenile rheumatoid arthritis. Arthritis Rheum 1986;29:274-81.

23 Kunnamo I, Kallio P, Pelkonen P. Incidence of arthritis in urban Finnish children. Arthritis Rheum 1986;29:1232-8.

24 Grund C, Haubitz I, Rausche A. MEDAS, System zur statistischen und graphischen Datenverarbeitung. Würzburg, 1995 .

25 deLuise VP, O'Leary MJ. Peripheral ulcerative keratitis related to Lyme disease. Am f Ophthalmol 1991;111:244-5.

26 Suttorp-Schulten MSA, Kuiper H, Kijlstra A, et al. Long-term effects of ceftriaxone treatment on intraocular Lyme borreliosis. Am F Ophthalmol 1993;116:571-5.

27 Breeveld J, Kuiper H, Spanjaard L, et al. Uveitis and Lyme borreliosis. Br f Ophthalmol 1993;77:480-1.

28 Preac-Mursic V, Pfister HW, Spiegel H, et al. First isolation of Borrelia burgdorferi from an iris biopsy. $\mathcal{F}$ Clin Neuroophthalmol 1993;13:155-61.

29 Lesser RL, Kornmehl EW, Pachner AR, et al. Neuroophthalmologic manifestations of Lyme disease. Ophthalmology 1990;97:699-706.

30 Scott IU, Silva-Lepe A, Siatkowski RM. Chiasmal optic neuritis in Lyme disease. Am F Ophthalmol 1997;123:1368.

31 Böhme M, Huppertz HI. Neuroborreliose mit Papillenprominenz und Abduzensparese. Monatsschr Kinderheilkd 1998;146:17-19.

32 Cassidy JT, Petty RE. Textbook of pediatric rheumatology. 3rd ed. Philadelphia: Saunders, 1995.

33 Dattwyler R, Volkman D, Luft B, et al. Seronegative Lyme disease: dissociation of specific $\mathrm{T}$ and $\mathrm{B}$ lymphocyte responses to Borrelia burgdorferi. N Engl f Med 1988;319: responses

34 Schubert HD, Greenebaum E, Neu HC. Cytologically proven seronegative Lyme choroiditis and vitritis. Retina 1994;14:39-42. 